\title{
An Experimental Study of the Pultrusion of Carbon Fiber-Polyamide 12 Yarn
}

\author{
S. WIEDMER* \\ Institut für Verbundwerkstoffe GmbH \\ Technical University of Kaiserslautern \\ D-67663 Kaiserslautern, Germany \\ M. MANOLESOS \\ Department of Mechanical Engineering and Aeronautics \\ University of Patras \\ 2655 Rio, Patras, Greece
}

\begin{abstract}
The present study reports about the pultrusion of a carbon fiberreinforced PA12 yarn containing discontinuous carbon and polyamide fibers. This is the first attempt to pultrude this material. Rectangular cross sectional profiles have been successfully produced using a self-designed pultrusion line. In a series of experiments, the pultrusion parameters, such as preheating method, die temperature, and especially the pulling speed, which represents a determining factor regarding a potential industrial application, are varied.

A complete characterization of each profile is conducted to examine the influence of processing parameters on the profile quality. The mechanical properties are evaluated by performing three-point bending as well as shear tests. The void content is also determined. The pulling speed seems to have the greatest influence on the profile quality. Under certain conditions of speed and temperature, the pultruded profiles exhibit good mechanical performance and a void content below $2 \%$. The shear strength reacts most sensitively to the process parameter variations and can be used as a quality criteria.
\end{abstract}

KEY WORDS: thermoplastic pultrusion, carbon fiber-polyamide 12 yarn.

*Author to whom correspondence should be addressed. E-mail: sandrine.wiedmer@ivw.uni-kl.de

Journal of THermoplastic COMPOSITE MAterials, Vol. 19-January 2006 


\section{INTRODUCTION}

Dultrusion is One of the sectors of the composite industry, which is growing steadily. Compared to the common composite production process, it offers the advantage of continuous production of profile with a constant cross section. Until now the process has been quite exclusively developed for thermosetting matrices, however, thermoplastic pultrusion shows a growth of interest, and considerable effort has been made over the last decade. This can be explained by certain advantages associated with thermoplastics, e.g., good mechanical performance, high temperature resistance, good chemical resistance, good recyclability, and their ability to be post-shaped [1-3].

The main problem while using thermoplastic matrices lies in the full impregnation of the fiber reinforcement, due to the high matrix melt viscosities. To overcome this problem, the distance of the polymer melt flow to the fiber reinforcement should be reduced. A large number of semifinished products has been developed where the matrices and reinforcement fibers are closely mingled, for instance in pre-impregnated tapes, hybrid yarns, or powder-impregnated bundles. Nevertheless, some difficulties still remain to achieve a good mingling of the matrix with the reinforcing fibers.

Recently, two companies have successfully developed new thermoplastic systems suitable for pultrusion. In both the cases, the matrix or resin used exhibits low viscosity, which enables a good flow between the reinforcing fibers and also a good wet out of the fiber, comparable with its thermoset counterparts. The end product, however, possesses the properties of the thermoplastic. The fulcrum pultrusion technology developed by Dow Chemical is based on a thermoplastic polyurethane [4,5] while Cyclics Corporation (Rensselaer, NY) uses a cyclics CBT resin, which polymerizes into poly(butylene terephthalate) (PBT) [5,6].

Some examples of experimental studies on the pultrusion process using different kinds of fiber-reinforced thermoplastics are given in [7-15]. The process parameters having an important effect on the properties of the pultruded composites, were found to be the pulling speed, the preheating section, and the cooling rate $[9,12,15]$.

In this study, the suitability for thermoplastic pultrusion of a carbon fiber (CF)-polyamide 12 (PA12) prepreg, consisting of discontinuous matrix and carbon fibers, was examined. A series of experiments has been conducted to evaluate the influence of the processing parameters, such as temperature and pulling speed, on the final properties of the profile, especially the mechanical properties. 


\section{EXPERIMENTAL}

\section{Material}

The pultrusion experiments have been conducted with a hybrid carbon fiber yarn, having the trade name TPFL from Schappe Techniques, France. This yarn combines discontinuous CF and PA12 fibers (Figure 1). The CF are produced from continuous yarn, which is broken up into discrete sections using a technique that removes the weak points of the fibers and improves their characteristics by increasing their tenacity and spinability. Table 1 gives some characteristics of the yarn. The melting point of the PA12 matrix was about $177^{\circ} \mathrm{C}$, as determined using differential scanning calorimetry (DSC).

\section{Pultrusion Facility}

Rectangular profiles have been manufactured using the self-designed pultrusion facility available at Institut für Verbundwerkstoffe, Kaiserslautern, Germany (Figure 2). From right to left, the CF-PA12 yarn is stored in a creel stand, then it is guided into the preheating chamber, where it is heated to a temperature near the melt temperature of the PA12 fibers. Immediately after preheating, the yarn bundles are pulled through the heating die where

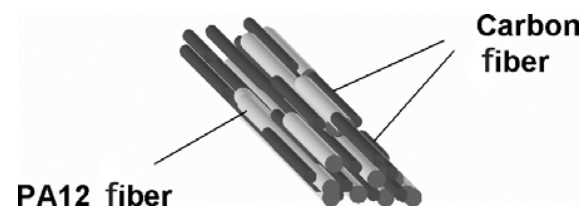

Figure 1. CF-PA12 hybrid yarn.

Table 1. Properties of CF-PA12 yarn.

\begin{tabular}{lcc}
\hline Properties & Unit & \\
\hline Tex & $\mathrm{g} / \mathrm{km}$ & 588 \\
Global carbon fiber volume content, $V_{\mathrm{F}}$ & $\%$ & 55 \\
Carbon fiber length, $L$ & $\mathrm{~mm}$ & $50-200$ \\
PA12 fiber length & $\mathrm{mm}$ & $75-85$ \\
Density: carbon fiber, $\rho_{\mathrm{M}} \quad \mathrm{g} / \mathrm{cm}^{3}$ & 1.77 \\
$\quad$ Matrix, $\rho_{\mathrm{F}}$ & $\mathrm{g} / \mathrm{cm}^{3}$ & 1.01 \\
Carbon fiber diameter, $d_{\mathrm{F}}$ & $\mu \mathrm{m}$ & 7 \\
PA12 fiber diameter, $d_{\mathrm{M}}$ & $\mu \mathrm{m}$ & 20 \\
\hline
\end{tabular}




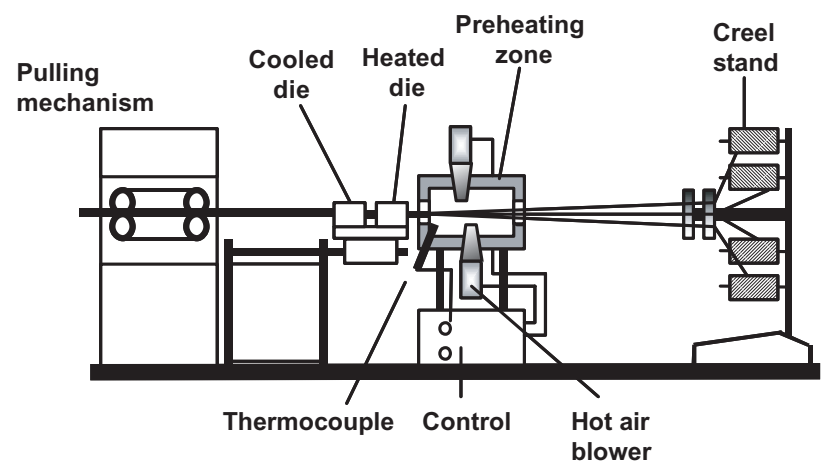

Figure 2. Scheme of the pultrusion line.

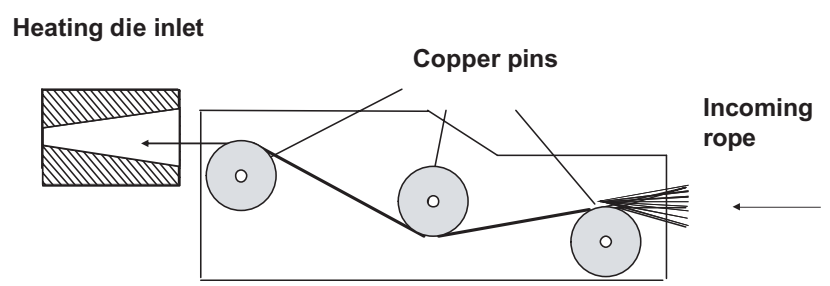

Figure 3. Contact pin heating device.

the polymer should melt before being fully consolidated in the cooling die. The profile is pulled through the different dies with a pulling device placed at the end of the pultrusion line.

The preheating zone is $0.6 \mathrm{~m}$ long, and its temperature can be varied. In the first set of experiments, hot convection air was used, afterwards preheating was applied using a heated contact pin device placed in this preheating chamber. The device consists of three copper pins heated with a heating cartridge (Figure 3). The fiber bundles were pulled over the first pin, under the second one, and finally over the third one. This enables a quick and homogeneous heat repartition over the fiber bundles and an accelerating preheating process $[14,16]$.

The die system consists of one heating die and one cooling die, separated by a narrow gap. The heated die cavity is $80 \mathrm{~mm}$ in length, and it is tapered at the entrance to facilitate the fiber supply and to build up some internal consolidating pressure profile. The final section geometry is $3.5 \times 10 \mathrm{~mm}^{2}$. The cooling die is placed after the heated die to ensure a good consolidation, using circulating water for cooling. The die consists of a lower and an upper part, which are screwed together, so that it is possible to vary the height of the cavity. During all the experiments conducted in the present study, the cooling die was maintained at room temperature. The dies were 
machined from tool steel, and the inside of their cavities were chromeplatinated. Hundred fiber bundles were required to fill the die cavity.

The temperature of the preheating systems, as well as of the heating die, are controlled steadily through the measurements of thermocouple probes located in the preheating chamber, in the contact pin device, and also in the heating die.

The processing parameters examined in this study were preheating and heating die temperature, as well as pulling speed.

\section{CHARACTERIZATION METHODS}

To quantify the effect of the processing parameters on the product quality, two types of mechanical tests were carried out, i.e., a three-point bending, and a shear test.

Flexural loading is the main loading type for profiles, and the flexural properties are influenced not only by the reinforcing fibers, but also by the matrix. In the present case, the flexural modulus and the flexural strength were determined. The span between the supports was $64 \mathrm{~mm}$, and the crosshead speed was $2 \mathrm{~mm} / \mathrm{min}$. The specimens were cut from the profile with a length of $80 \mathrm{~mm}$ and a cross section about $3.5 \times 10 \mathrm{~mm}^{2}$. Five specimens from each pultrusion run were tested.

The shear strength is known to be more sensitive to process variations than the bending strength or modulus, because numerous parameters influence this property: the fiber-matrix adhesion, the properties of the matrix and the fibers, the void content, and the matrix crystallinity $[9,16]$. It was determined using an interlaminar shear device (ISD) also called compression shear device (CSD) developed by Lauke et al. [17,18] for small sections of filament wound rings. It is, however, also suitable for short, straight specimens. The ISD test involves shearing a specimen to failure along the direction of the fibers by applying a compression load. The principle of the ISD is shown in Figure 4. A 10-mm-long specimen is clamped between two shear knifes, with the fibers oriented parallel to the shear area. The device is installed in a static testing machine, which applies a load. The testing speed is fixed at $1 \mathrm{~mm} / \mathrm{min}$. In the calculation of the shear strength, not only the force and the cross section, but also the cantilever ratio has to be taken into account.

The average shear strength $\sigma$ is calculated by Equation (1):

$$
\sigma=\frac{F_{\text {eff }}}{h \times b}
$$

where $F_{\text {eff }}=\left(l_{\mathrm{k}} / l_{\mathrm{s}}\right) \times F$, and $h$ is the length of the specimen; $b$ is the width of the specimen and $F$ is the maximum load or load on the specimen to failure. 


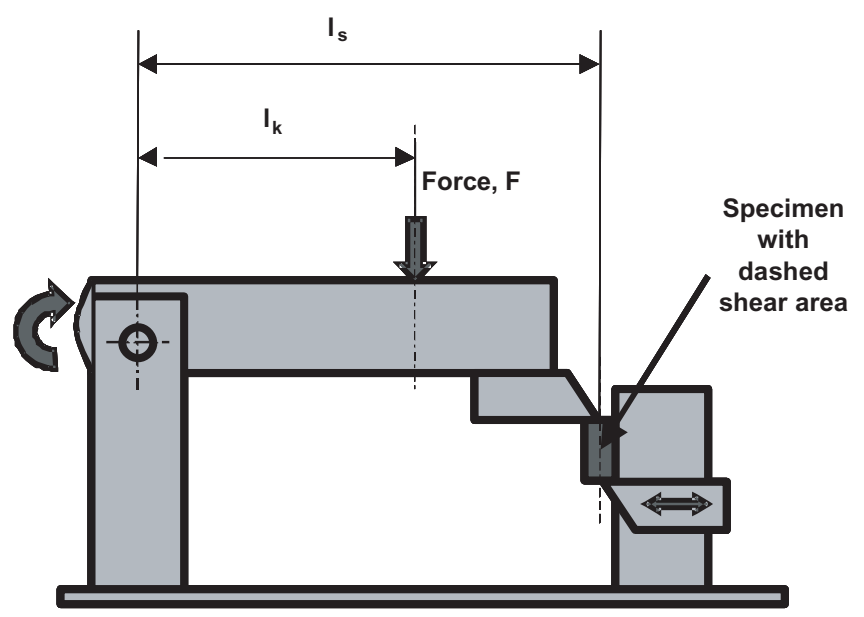

Figure 4. Shear testing device.

The ISD test offers the advantage of being a very simple test to conduct. Equation (1) assumes that the shear stress through the specimen is uniform. This would require a specimen without defects and a homogeneous stress distribution, which is in practice not possible. But it gives a quick and simple estimate of the average shear strength of the composite at failure, since it is easy to determine when the specimen fails due to the brittle nature of the failure. It corresponds directly to Mode II fracture. Additionally, it gives a simpler and better-defined shear stress distribution, when compared to a standard short beam shear (SBS) test [19]. The latter leads to a complex failure mechanism, a pure shear stress state is not induced anywhere and it introduces an uncertainty in determining the failure stress. On the other hand, the ISD test specimen leads to failure in pure shear. The failure occurs in the center region and the stress distribution shows a relatively uniform shear stress along the centerline, which is the expected delamination region [20]. A limitation of the test is that the shear modulus cannot be determined.

The void content was determined by the gravimetrical method. Initially, the specimen density was determined using the buoyancy-flotation method. The weight measurements of each specimen were carried out once in air and once in a liquid with a certain density (in this case water), and the experimental density $\left(\rho_{\text {arch }}\right)$ of the specimen was then evaluated using Equation (2):

$$
\rho_{\mathrm{arch}}=\frac{m_{\mathrm{a}}}{m_{\mathrm{a}}-m_{\mathrm{w}}} \rho_{\mathrm{w}}
$$


where, $m_{\mathrm{a}}$ is the weight of the specimen in air, $m_{\mathrm{w}}$ is the weight of the specimen in water, and $\rho_{\mathrm{w}}$ is the density of the liquid.

Then, assuming the same specimen to be void free, the theoretical density $\left(\rho_{\text {th }}\right)$ was calculated using the rule of mixture (Equation (3)):

$$
\rho_{\mathrm{th}}=V_{\mathrm{F}} \rho_{\mathrm{F}}+\left(1-V_{\mathrm{F}}\right) \rho_{\mathrm{M}}
$$

where $\rho_{\mathrm{F}}$ and $\rho_{\mathrm{M}}$ are the densities of the carbon fiber and the matrix, respectively, and $V_{\mathrm{F}}$ and $V_{\mathrm{M}}$ refer to their volume contents in the specimen.

For the determination of the fiber volume fraction, the specimen was put in $\approx 100 \mathrm{~mL}$ formic acid for about $3 \mathrm{~h}$ at $180^{\circ} \mathrm{C}$. After this period, the matrix was totally removed. After cooling, formic acid and the dissolved matrix were filtered using a small glass filter with a porous bottom. The residual carbon fibers were washed with ethanol, dried in an oven at $100^{\circ} \mathrm{C}$ for a couple of hours, and finally weighed at room temperature. The void content was calculated from the ratio of experimental density theoretical density.

\section{RESULTS AND DISCUSSION}

The influence of the preheating method was studied by conducting experiments at increasing pulling speed. Earlier studies have shown the importance of a sufficient matrix preheating on the final impregnation quality $[9,13,15]$. During the pultrusion of GF-PP yarn, a preheating temperature slightly below the melting temperature of polypropylene was found to be most appropriate [13]. Based on these results, the preheating temperature was chosen at $170^{\circ} \mathrm{C}$, which corresponds to a temperature slightly below the melting point of the PA12.

Here, it is important to mention the problem encountered with yarns containing discontinuous fibers. As the matrix softens, the yarn automatically loses its strength and it runs the risk that some fibers break. Attention should be paid to avoid a complete melting of the polymer in the preheating chamber. On the other hand, a sufficiently high preheating temperature offers the advantage that the matrix viscosity is low enough, which leads to a decrease of the pulling force in the heating die and also reduces the risk of fiber breaking in the heating die. A load cell placed on line with the die system permitted control of the pulling force during our experiments. However, it served only for a qualitative estimate since it was impossible to record the pulling force.

At a preheating temperature of about $170^{\circ} \mathrm{C}$, the matrix did not melt before entering the heating die and the yarn retained a certain strength. 

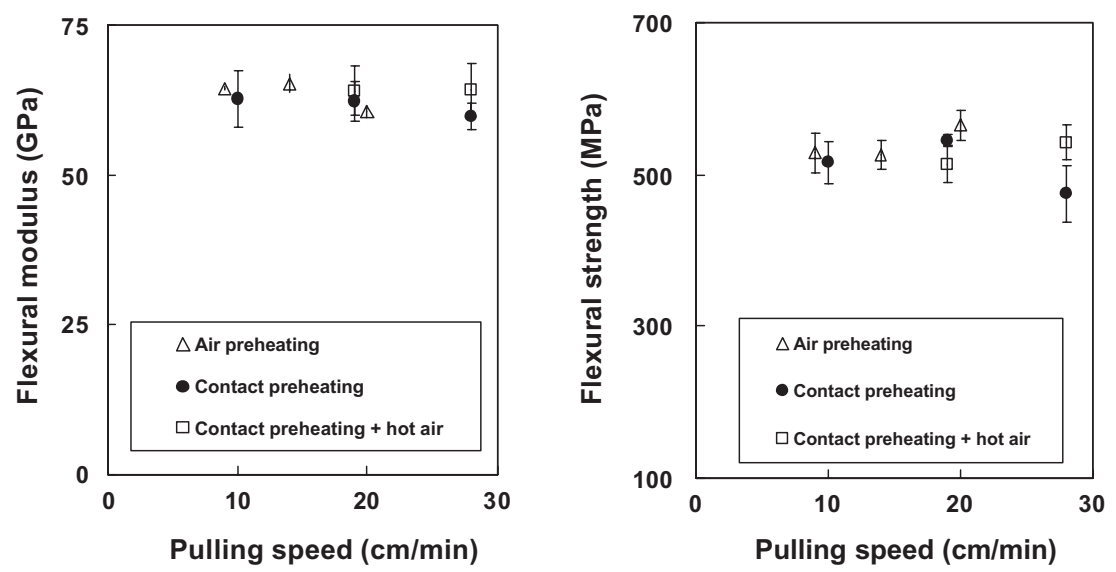

Figure 5. Flexural strength and flexural modulus vs pulling speed using different preheating methods.

However, experiments conducted at a low speed and a preheating temperature above $180^{\circ} \mathrm{C}$ showed that the matrix started to melt in the vicinity of the contact pins device, and some yarns broke.

A set of experiments were conducted using different preheating methods. The preheating temperature was $170^{\circ} \mathrm{C}$, the heating die temperature was $205^{\circ} \mathrm{C}$. Flexural strength and flexural modulus as a function of pulling speed and preheating method are represented in Figure 5, but they did not exhibit any significant variation within the speed range studied. However, the shear strength reacts more sensitively. In Figure 6, we can see that at a low pulling speed no significant difference is observed between using air preheating or contact pins. An increase in the pulling speed clearly results in a decrease in shear strength, as well as an increase in the void content by using hot air for preheating. However, by using the contact pin device, the shear strength 'starts' to decrease at a pulling speed of around $20 \mathrm{~cm} / \mathrm{min}$ while the void content increases. Finally, while using a combination of hot air ovencontact pins, it is evident that higher shear strength and low void content are achieved even at high pulling speeds, which confirms the efficiency of such a preheating combination [16], where heat transfer is considerably enhanced.

Further experiments were conducted systematically to determine the influence of pulling speed and heating die temperature on the profile properties. Within the course of this study, contact preheating combined with hot air, both at a temperature of $170^{\circ} \mathrm{C}$, was used.

The void content versus heating die temperature at various pulling speeds is shown in Figure 7 (note that $v$ refers to the pulling speed on the figures). It is obvious that an increase in the pulling speed requires a higher 

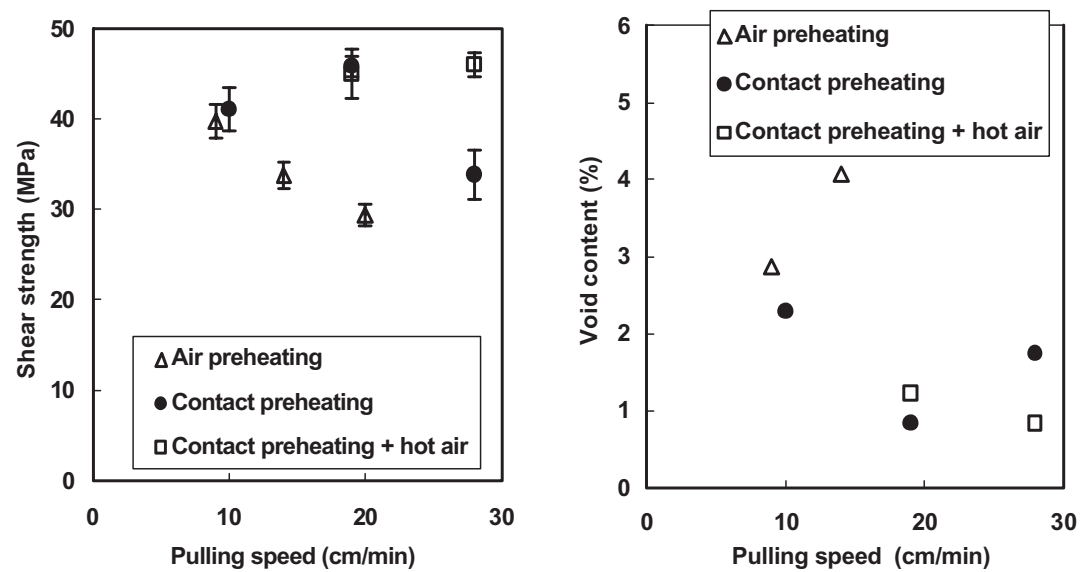

Figure 6. Shear strength and void content vs pulling speed using different preheating methods.

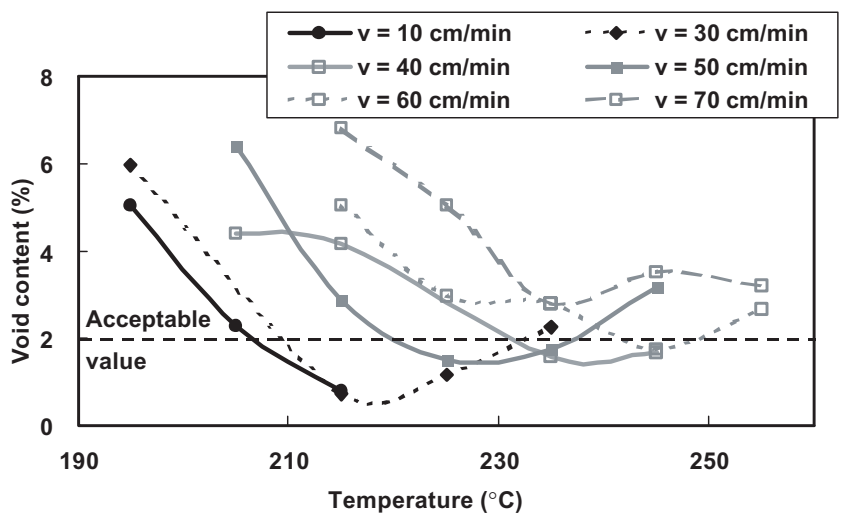

Figure 7. Void content as a function of heating die temperature.

heating die temperature to sufficiently melt the polymer, to achieve an acceptably low void content. It should be pointed out that a void content up to $2 \%$ constitutes a commonly acceptable value for composite material (but not for aerospace). This is confirmed by the DIN EN 13706 standard [21], which reports that $2 \%$ of internal porosity constitutes an acceptable limit for the pultruded profiles. However, at a low pulling speed, a further increase in the heating die temperature leads to an increase in the void content. This can be explained by the fact, that during the process the matrix viscosity decreases so much, that the matrix can flow back from the die, or 
the matrix can even start to degrade. Furthermore, the figure shows that at pulling speeds above $60-70 \mathrm{~cm} / \mathrm{min}$, a low void content can no longer be reached, since the residence time of the material in the die system, as well as in the preheating zone, is too short to allow good melting. Here, an increase in the preheating zone temperature could certainly be advantageous at a high pulling speed, on the condition that the matrix does not melt completely. The results of such investigations are not reported in the present study.

One should note that the tool temperature and the pulling speed have a combined influence on the impregnation quality. First, the temperature influences the matrix viscosity and, consequently, the pressure inside the die. An increase in the temperature leads to a decrease of the matrix viscosity, which in turn tends to reduce the pressure. In general, a sufficiently low viscosity combined with a sufficiently high pressure should act favorably on the fiber impregnation. Second, the pulling speed determines the residence time of the polymer in the die system and, consequently, influences the temperature the polymer can reach, which in turn influences the matrix viscosity and the pressure, as developed earlier. However, as it is demonstrated in $[9,13]$, an increase in the pulling speed generally leads to an increase of the pressure in the tapered entrance of the heating die, which benefits the impregnation process. On the other hand, high pulling speed can lead to insufficient consolidation time. However, it should be pointed out that at low pulling speed the polymer matrix is exposed to high temperature over a long time, which can lead to degradation.

One should also consider the pulling force encountered in the pultrusion process. The different mechanisms contributing to the pulling force are known to be the friction resistance, which refers to the friction of the materials against the die wall; the viscous resistance, which is the force generated by the shear flow in the thin region between the pultruded mass and the die wall; as well as the compaction resistance, which represents the resistance due to the compaction of the fiber and of the matrix in the tapered angle of the heating die. In the pulling force model, presented by Aström and Pipes [22], it is demonstrated that the viscous and compaction components increase, and, consequently, the pulling force, by increasing the pulling speed. Similarly, the pulling force increases, if the die temperature is too low, due to a high matrix viscosity. As mentioned, a serious increase in the pulling force can cause fiber breaking and thus be fatal to the process.

Furthermore, at too low viscosity, e.g., due to the high temperature at a low pulling speed, and/or high pressure, the matrix tends to flow back from the heating die and accumulate at the entrance.

All the aforementioned reasons explain the difficulty to clearly separate the influence of both, the pulling speed, and the die temperature. 


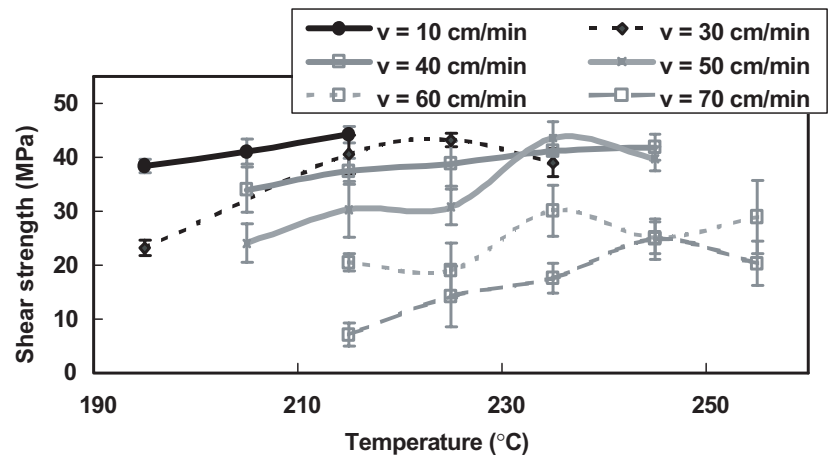

Figure 8. Shear strength as a function of heating die temperature.

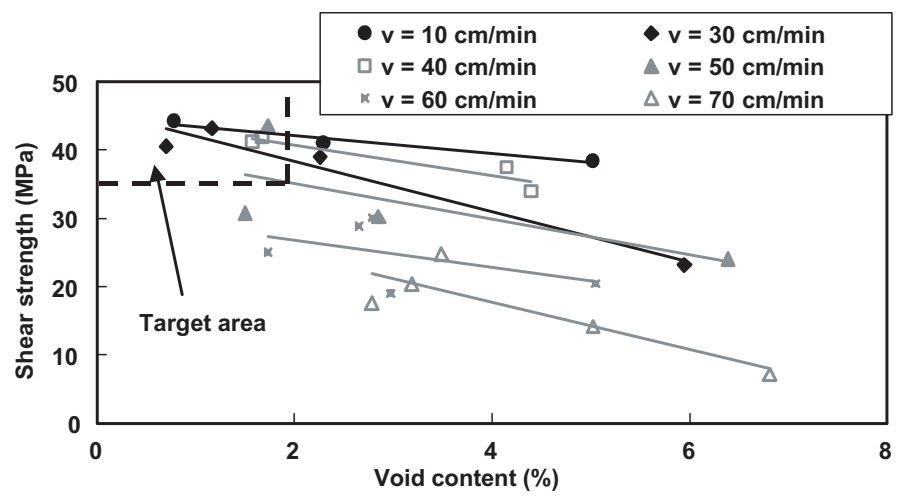

Figure 9. Shear strength as a function of void content.

Figures 8 and 9 display the effects of the processing parameters on the shear strength. In Figure 8, it can be observed that the shear strength is strongly dependent on the pulling speed; an increase in the pulling speed causes a decrease in the shear strength, whereas the effect of the heating die temperature is less pronounced than in the case of the void content. A possible explanation is that the preheating temperature was already too high; in [8] it is observed that the heating die temperature shows only a significant influence on the mechanical properties, if the preheating temperature is set to a quite low level.

Figure 9 shows the shear strength as a function of the void content and pulling speed. Here, it should be noted that the profiles, which exhibit similar void content, but have been pultruded at different pulling speed, exhibit different shear strength values. It suggests that the shear strength is not only dependent on the void content, but also on the pulling speed, 
as stated earlier. The pulling speed strongly influences the material properties, like for instance the crystallinity. Finally, we defined a target area (Figure 9) using shear strength values exceeding $80 \%$ of the maximal achieved shear strength and maximal porosity $<2 \%$. Here the maximal shear strength achieved is around $45 \mathrm{MPa}$.

Effects of the processing parameters on the flexural properties are depicted in Figures 10 and 11. The pulling speed has similar influence on the flexural properties as well as on the shear strength, where an increase in the processing speed automatically causes a decrease in the flexural properties. However, the effect of heating die temperature is less pronounced. A drop is observed only after exceeding a certain temperature. As mentioned earlier, a possible explanation was that the preheating temperature was already too high so that the heating die temperature showed no significant influence on the mechanical properties.

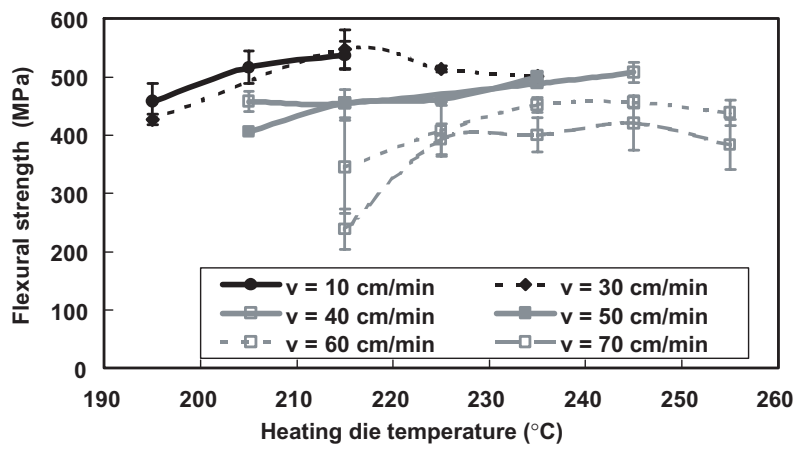

Figure 10. Flexural strength as a function of heating die temperature.

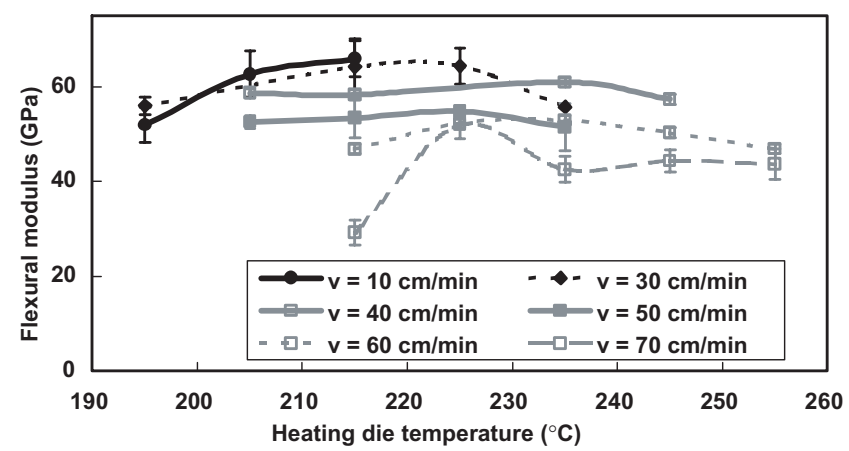

Figure 11. Flexural modulus as a function of heating die temperature. 
The longitudinal modulus of the fiber-reinforced composites can be evaluated theoretically. In the case of a unidirectional continuous fiber reinforcement, the rule of mixtures (Equation (4)) can be applied [23]:

$$
E_{1}=E_{\mathrm{F}} \times V_{\mathrm{F}}+E_{\mathrm{M}} \times\left(1-V_{\mathrm{F}}\right)
$$

where $E_{\mathrm{F}}$ and $E_{\mathrm{M}}$ are the modulus of the carbon fibers and the PA12 matrix, respectively, and $V_{\mathrm{F}}$ is the carbon fiber volume content.

However, if the fibers are discontinuous, the modulus can be estimated using Equation (5) [23]:

$$
E_{1(\mathrm{disc})}=\frac{E_{\mathrm{M}} \times\left(1+\zeta \times \eta \times V_{\mathrm{F}}\right)}{\left(1-\eta \times V_{\mathrm{F}}\right)}
$$

where $\zeta=2 \times\left(L / d_{\mathrm{F}}\right)$ and $\eta=\left(\left(E_{\mathrm{F}} / E_{\mathrm{M}}\right)-1 /\left(E_{\mathrm{F}} / E_{\mathrm{M}}\right)+\zeta\right)$.

The values of $V_{\mathrm{F}}$ and $d_{\mathrm{F}}$ are given in Table 1 . Considering $E_{\mathrm{F}}=238 \mathrm{GPa}$, $E_{\mathrm{M}}=1.2 \mathrm{GPa}$, and an average carbon fiber length $L$ of $100 \mathrm{~mm}$, we calculated the modulus from Equations (4) and (5). In both the cases, the numerical value for $E_{1}$ is $\simeq 131 \mathrm{GPa}$. This means that, although the carbon fibers in the material are discontinuous, the mechanical properties are similar to those of a continuous fiber-reinforced composites. This can be explained by the high aspect ratio of the carbon fiber, i.e., the ratio of fiber length to fiber diameter. It is obvious that the modulus determined from the experiments (Figure 11) is about half of the calculated value. One should note that we experimentally determined the flexural modulus, while the value calculated earlier referred to the Young's modulus, or tensile modulus. For this reason we cannot directly compare the theoretical and experimental moduli. One should mention that using long fiber instead of continuous fiber in thermoplastic composites offers some advantages in the postshaping process.

A simple visual inspection of the different specimens revealed an important variation in the surface quality. At a low pulling speed, the pultruded profiles exhibited high roughness, whereas a further increase of the pulling speed led to a profile with a relatively smooth surface, like a rich matrix layer. It is shown in Figure 12, on the upper profile that it is possible to distinguish some carbon fibers on the surface, whereas the lower specimen exhibited a relatively glossy surface. In addition to the high roughness, some profiles pultruded at low speed exhibited a final cross section slightly different from the final heating die section of $3.5 \times 10 \mathrm{~mm}^{2}$. These results were confirmed by the microscopic analysis, in the micrographs from Figure 13, one can clearly distinguish the difference in surface roughness. This phenomenon can be explained by the fact that at a 


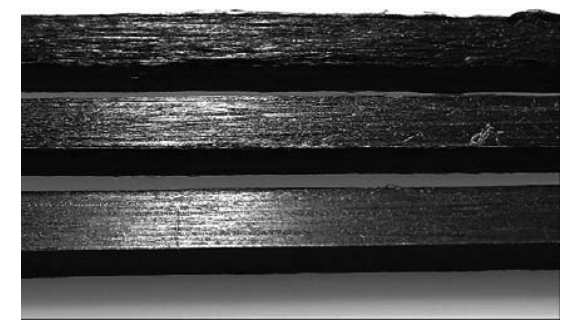

Figure 12. Profiles manufacturing at different pulling speed; from the top to bottom: $v=9 \mathrm{~cm} / \mathrm{min}, 14 \mathrm{~cm} / \mathrm{min}$, and $28 \mathrm{~cm} / \mathrm{min}$, respectively.
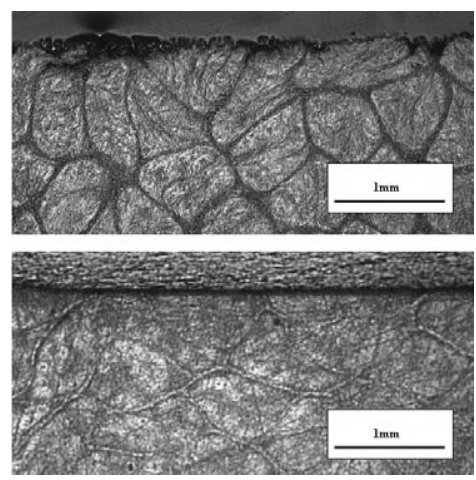

Figure 13. Micrographs showing the cross section from profiles pultruded at pulling speed from $10 \mathrm{~cm} / \mathrm{min}$ (on the top) and $20 \mathrm{~cm} / \mathrm{min}$ (on the bottom).

low speed, the profile spent more time in the gap between the heating and cooling dies. Due to the negative thermal expansion coefficient of the carbon fiber, the profile tends to expand at the exit of the heating die with the consequence that the profile can enter the cooling die only if the latter is slightly open. One should also take the shear force between the outer part of the profile and the die wall into account. At high pulling speed, the pulling force increases and the matrix tends to be "stretched" which could explain the smooth surface. Additionally, one should consider the cooling process. At low pulling speeds, the profile spent enough time in the cooling die and could solidify over its entire cross section. However, at a high pulling speed, only the outer layer of the profile was solidified after leaving the die and its center cooled down slowly. This problem was not investigated here in detail but this could also partly explain the difference observed in the surface quality. 


\section{CONCLUSIONS}

In this study, the first attempt to pultrude the profiles from a CF-PA12 yarn with discontinuous carbon fibers was successfully conducted. The influence of process parameters on the profile quality was systematically investigated. A satisfactory void content below $2 \%$ was possible to achieve. The pulling speed seems to have the greatest influence on the profile quality. The interlaminar shear strength was the most sensitive to process parameter variation and can easily be used as a quality control parameter.

In spite of the presence of discontinuous fibers in the yarn, profiles with good mechanical quality were produced. This offers a new application field to this material and consequently open a new market for the material supplier. Furthermore, it should be interesting to exploit the possibility of post-shaping the profile.

\section{ACKNOWLEDGMENTS}

Special thanks are due to Schappe Techniques, Charnoz, France, for supplying the material. Furthermore, the authors thank the Stiftung Industrie Forschung, Köln, Germany (Fellowship No. T 3/2002 of S. Wiedmer) for their financial support. In addition, the authors are grateful to Professor $\mathrm{K}$. Friedrich for his valuable comments on the results of this study and on the preparation of the manuscript.

\section{REFERENCES}

1. Jürss, D. (1995). Thermoplastpultrusion-Strangziehen von endlosfaserverstärkten Profilen mit thermoplastischen Matrixwerkstoff. Doctoral Thesis. RWTH, Aachen, Germany.

2. Blaurock, J. and Michaeli, W. (1996). Pultrusion von Endlosfaserverstärkten Profilen mit thermoplastischer Matrix, In: Proceedings 27, Internationale AVK-Tagung, Baden-Baden, pp. B20-1-B20-8.

3. Tomlinson, W.J. and Holland, J.R. (1993). Advantages of Pultruding Thermoplastics, Reinforced Plastics, 37(10): 46-49.

4. Edwards, C. (2001). Thermoplastic Pultrusion Promises New Synergies, Reinforced Plastics, 45(4): 34-39.

5. Hranac, C.K. (2001). New Thermoplastic Technologies Heat Up Pultrusion, Composites Technology, 7(1): 32-35.

6. Lohmiller, J. (2004). Cyclics Thermoplastics - New Possibilities in Composites, In: Proceedings IVW-Kolloquium, Kaiserslautern, Germany, 5-6 October, pp. 76-80.

7. Taylor, R. and Thomas, M. (1990). High Speed Pultrusion of Thermoplastic Composites, In: Proceedings 22nd International SAMPE Technical Conference, Vol. 22, Anaheim, California, USA, pp. 78-87.

8. Bechtold, G. and Friedrich, K. (1997). Pultrusion of Glass Fiber/Polypropylene Composites, In: Karger-Kocsis, J. (ed.), Polypropylene: An A-Z Reference, pp. 686-693, Chapman \& Hall Ltd., London. 
9. Kerbiriou, V. (1997). Imprägnieren und Pultrusion von thermoplastischen Verbundprofilen, VDI-Verlag, Düsseldorf.

10. Devlin, B.J., Williams, M.D., Quinn, J.A. and Gibson, A.G. (1991). Pultrusion of Unidirectional Composites with Thermoplastic Matrices, Composite Manufacturing, 2(3/4): 203-207.

11. Carlsson, A. and Aström, B. (1998). Experimental Investigation of Glass Fiber Reinforced Polypropylene Composites, Composites Part A-Applied Sciences, 29A(5-6): 585-593.

12. Vaughan, J.G., Dillard, T.W. and Seal, E. (1990). A Characterization of the Important Parameters for Graphite/PEEK Pultrusion, Journal of Thermoplastic Composite Material, 3(2): 131-149.

13. Bechtold, G. (2000). Pultrusion von geflochtenen und axial verstärkten ThermoplastHalbzeugen und deren zerstörungsfreie Porengehaltsbestimmung, Dissertation Institut für Verbundwerkstoffe GmbH, Universität Kaiserslautern.

14. Miller, A.H., Dodds, N. and Gibson, A.G. (1997). High Speed Pultrusion of Thermoplastic Matrix Composites via the Commingled and Dry Powder Impregnation Routes, In: Proceedings International Conference on Advanced Composites, ICAC 97', Glasgow, UK, pp. 169-192.

15. Aström, B.T., Larsson, P.H., Hepola, P.J. and Pipes, R.B. (1994). Flexural Properties of Pultruded Carbon/PEEK Composites as a Function of Processing History, Composites, 25(8): 814-821.

16. Bechtold, G., Wiedmer, S. and Friedrich, K. (2002). Pultrusion of Thermoplastic Composites - New Developments and Modelling Studies, Journal of Thermoplastic Composite Materials, 15(5): 443-465.

17. Lauke, B., Schneider, K. and Friedrich, K. (1992). Interlaminar Shear Strength Measurement of Thin Composite Rings Fabricated by Filament Winding, In: Proceedings 5th European Conference on Composite Materials 'ECCM-5', EACM-Publication, Bordeaux, pp. 423-428.

18. Schneider, K., Lauke, B. and Beckert, W. (2001). Compression Shear Test (CST) - A Convenient Apparatus for the Estimation of Apparent Shear Strength of Composite Material, Applied Composite Materials, 8(1): 43-62.

19. ASTM Committee (1995). Standard Test Method for Apparent Interlaminar Shear Strength of Parallel Fiber Composites by Short-Beam Method, ASTM D2344-84.

20. Rosseli, F. and Santare, M.H. (1997). Comparison of the Short Beam Shear (SBS) and Interlaminar Shear Device (ISD) Test, Composites Part A-Applied Sciences, 28A(6): $587-594$.

21. DIN, Deutsches Institut für Normung (2003). Spezifikationen für Pultrudierte Profile, Teil 2: Prüfverfahren und allgemeine Anforderungen, DIN EN 13706-2.

22. Aström, B.T. and Pipes, R.B. (1993). A Modeling Approach to Thermoplastic Pultrusion I: Formulation of Models, Polymer Composites, 14(3): 173-183.

23. Hull, D. (1981). An Introduction to Composite Materials, Cambridge University Press, Cambridge. 